\title{
PENGATURAN REGULATOR AUTOTRAFO 3 FASA BERBASIS MINI PLC ZELIO
}

\author{
Bony M. Farid ${ }^{1}$, Mohamad Mukhsin ${ }^{2}$, Faqih Rofii ${ }^{3}$ \\ ${ }^{1}$ Fakultas Teknik, Jurusan Teknik Elektro, Universitas Widyagama Malang \\ ${ }^{2}$ Fakultas Teknik, Jurusan Teknik Elektro, Universitas Widyagama Malang \\ ${ }^{3}$ Fakultas Teknik, Jurusan Teknik Elektro, Universitas Widyagama Malang \\ Email: bonymvar@gmail.com
}

\begin{abstract}
Abstrak
Suatu sistem tenaga listrik dikatakan memiliki keandalan yang tinggi apabila sistem tersebut mampu menyediakan pasokan energi listrik yang dibutuhkan oleh konsumen secara kontinyu dan tegangan yang stabil. Autotrafo variabel (variac) memiliki fungsi untuk menstabilkan tegangan sehingga tegangan keluaran tetap stabil meskipun terjadi gangguan. Sensor Arus (WCS 1800) juga digunakan sebagai pengaman beban, hasil pembacaan dari sensor arus berpengaruh pada PLC zelio untuk mematikan kontaktor. Respon yang dihasilkan dari alat ini ketika kondisi sistem online dari set point tegangan 380 volt ( $\pm 1.3 \%)$ pada program FBD yang dibuat, tegangan input yang kurang atau lebih dari 380 volt sampai kembali ke set point variable tegangan 380 volt ketika tidak berbeban yaitu pada saat under voltage adalah \pm 0.40 sekon dengan persen error adalah $\pm 0.20 \%$ dan pada saat over voltage adalah \pm 0.53 sekon dengan persen error adalah $\pm 0.15 \%$. Serta ketika berbeban yaitu pada saat under voltage adalah \pm 0.44 sekon dengan persen error adalah $\pm 0.20 \%$ dan pada saat over voltage adalah \pm 0.55 sekon dengan persen error adalah \pm 0.20 $\%$.
\end{abstract}

Kata kunci : Undervoltage, Overvoltage, Autotrafo, Sensor tegangan, Sensor Arus, dan Motor dc

\begin{abstract}
An electric power system is said to have high reliability if the system is able to provide the electricity supply needed by consumers in a continuous and stable voltage. Variable autotrafo (variac) has a function to stabilize the voltage so that the output voltage remains stable despite interference. Flow Sensor (WCS 1800) is also used as a load safety, the result of reading from the current sensor influences the zelio PLC to turn off the contactor. The response generated from this tool is when the online system condition of the set point voltage of 380 volts (+ $1.3 \%)$ in the FBD program is made, the input voltage is less than 380 volts until it returns to the set point variable voltage 380 volts when not loaded ie when under voltage is +0.40 seconds with a percent error is $+0.20 \%$ and when over voltage is +0.53 seconds with a percent error is $+0.15 \%$. And when loaded, that is, when under voltage is +0.44 seconds with a percent error is + $0.20 \%$ and when over voltage is +0.55 seconds with an error percentage is $+0.20 \%$.
\end{abstract}

Keywords: Undervoltage, Overvoltage, Autotrafo, Voltage Sensor, Flow Sensor, and dc Motor 


\section{PENDAHULUAN}

Pada dasarnya dalam suatu sistem rangkaian listrik, kontinuitas supply listrik sangat diperlukan. Under voltage atau Over voltage adalah gangguan dalam supply listrik [1]. Jika tegangan ini dihubungkan ke peralatan listrik dapat mengganggu operasional dari peralatan-peralatan tersebut atau bahkan dapat merusaknya karena suplai tegangan yang tidak stabil, dampaknya menyebabkan kenaikan arus pada beban yang sama, sehingga belitan pada beban akan mengalami pemanasan lebih. Sementara itu tegangan yang lebih dapat menyebabkan umur isolasi menurun. Oleh karena itu sistem supply tegangan ke peralatan listrik diharapkan selalu stabil agar peralatan listrik mempunyai lifetime yang cukup lama [3].

Autotrafo variabel (variac) adalah salah satu jenis transformator yang salah satu titik sadap atau "tap" nya dapat digeser, sehingga autotrafo memiliki fungsi sama dengan AVR (Automatic Voltage Regulator) sebagai stabilisator tegangan yang dapat diatur tegangan keluarannya. Namun autotrafo ini masih menggunakan tuas manual. Untuk mengatasi permasalahan tersebut, maka diperlukan alat untuk menggerakkan dan mengontrol tuas autotrafo, sehingga dapat menaikkan dan menurunkan tegangan keluaran secara terkendali [4].

Berdasarkan riset yang pernah dilakukan oleh M. Abdul Aziz dkk, perbedaannya ada pada set point regulator autotrafo fix variabel (telah ditetapkan) berbasis mikrokontroller [1,2]. Pada skripsi ini akan dikembangkan alat yang dapat diatur set point regulator autotrafo variabel berbasis zelio sesuai dengan yang dikehendaki. Alat ini juga dilengkapi sensor tegangan dan sensor arus yang dapat mendeteksi under voltage, over voltage serta arus lebih. Pada sensor tegangan digunakan rangkaian pembagi tegangan sebagai pendeteksi tegangan. Dan pada sensor arus digunakan sebagai pengaman peralatan ketika ada arus lebih [5]. Output dari sensor tegangan dan sensor arus tersebut diolah ke dalam mini PLC Zelio sebagai kontroler untuk memerintahkan motor dc yang sudah dikopel dengan gearbox untuk berputar memutarkan tuas autotrafo. Keunggulan PLC Zelio Logic Smart Relay selain sudah banyak digunakan untuk aplikasi industri, plc ini murah dan mampu di program tidak hanya menggunakan ladder diagram melainkan juga Function Block Diagram (FBD). Oleh karena itu pemrograman mini PLC Zelio diharapkan dapat bekerja sesuai dengan desain yang dibuat [6]. Untuk mendesain alat mekanik ini dibutuhkan perhitungan perbandingan gigi reduksi gearbox yang benar antara motor dc dengan tuas Autotrafo [7], pembuatan driver untuk motor dc serta penambahan limit switch sebagai pengaman pada tuas autotrafo [8]. Hasil dari alat yang dibuat dapat diaplikasikan untuk peralatan elektronik, listrik atau motor-motor 3 phasa yang bekerja 24 jam non-stop dan untuk keperluan uji LAB.

\section{STUDI PUSTAKA}

\subsection{Stabilitas Tegangan}

Kestabilan tegangan adalah kemampuan sistem untuk menjaga tegangan sistem pada seluruh bus tetap berada dalam batas stabil saat kondisi normal atau setelah terjadi gangguan. Undervoltage dan Overvoltage merupakan salah satu bentuk dari ketidakstabilan sistem dalam melakukan penyaluran energi listrik ke konsumen [9].

Demi mendapatkan kinerja sistem yang baik dengan tegangan sistem yang selalu stabil berdasarkan SPLN No. 1:1995 Pasal 4 tentang ketentuan variasi tegangan pelayanan dimana tegangan yang diijinkan hanya sebesar $-10 \% \mathrm{~s} / \mathrm{d}+5 \%$ dan SPLN 12/1978 tentang karakteristik jaringan listrik yang handal pada poin 2 
adalah mempunyai kualitas daya yang baik, meliputi kapasitas daya yang memadai, tegangan yang selalu konstan dan frekuensi yang selalu konstan [10].

\subsection{Sensor Tegangan}

Sensor tegangan digunakan untuk mendapatkan parameter tegangan antar fasa sehingga dapat mengetahui besar tegangan fasa-fasa. Sensor tegangan ini menggunakan potensial transformer dan resistor pembagi tegangan dipasang secara paralel antara phasa dengan netral. Fungsi resistor ini adalah untuk menurunkan tegangan dari tegangan sumber menjadi tegangan yang dikehendaki. Dapat dilihat gambar rangkaian resistor pembagi tegangan pada Gambar 2.1.

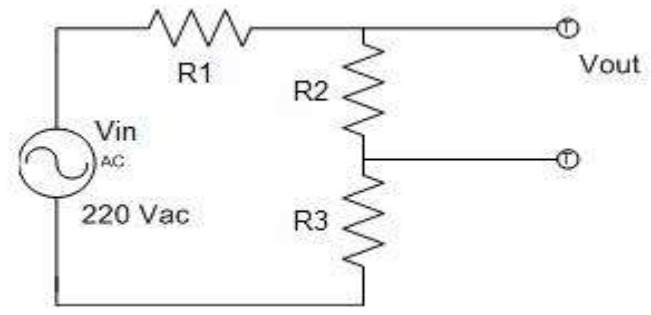

Gambar 2.1 Rangkaian Resistor Pembagi Tegangan

$$
\text { Vout }=\frac{\mathrm{R} 2}{\mathrm{R} 1+\mathrm{R} 2+\mathrm{R} 3} \times \mathrm{Vin}
$$

Rangkaian resistor pembagi tegangan menggunakan 3 resistor dipasang seri (R1, R2 dan R3). Dengan mengambil tegangan pada R2 didapatkan tegangan output sesuai rumusan diatas. Tegangan keluaran dari rangkaian resistor pembagi tegangan digunakan untuk masukan pengkondisian sinyal (ADC) pada mini PLC zelio [11].

\subsection{Sensor Arus}

Pengukuran arus biasanya membutuhkan sebuah resistor shunt yaitu resistor yang dihubungkan secara seri pada beban dan mengubah aliran arus menjadi tegangan. Tegangan tersebut biasanya diumpankan ke current transformer terlebih dahulu sebelum masuk ke rangkaian pengkondisi sinyal (ADC).

WCS 1800 adalah Teknologi yang diterapkan oleh Winson merupakan suatu IC terpaket yang mana berguna untuk menggantikan trafo arus yang relatif besar dalam hal ukuran. Cara kerja sensor WCS 1800 adalah arus yang dibaca mengalir melalui kabel tembaga yang terdapat di dalamnya menghasilkan medan magnet yang di tangkap oleh integrated Hall IC dan diubah menjadi tegangan proporsional. Sensor ini telah dilengkapi dengan rangkaian penguat operasional, sehingga sensitivitas pengukuran arusnya meningkat dan dapat mengukur perubahan arus yang kecil. Sensor ini digunakan pada aplikasi-aplikasi di bidang industri, komersial, maupun komunikasi. Contoh aplikasinya antara lain untuk sensor kontrol motor, deteksi dan manajemen penggunaan daya, sensor untuk catu daya tersaklar, sensor proteksi terhadap arus lebih, dan lain sebagainya [12]. Pada Gambar 2.2 adalah Function Blok Diagram dari Sensor Arus WCS1800. 


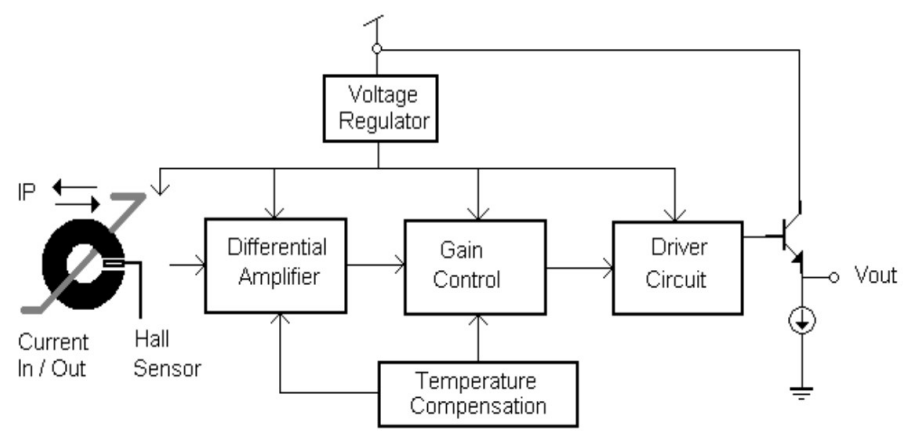

Gambar 2.2 Blok Diagram WCS 1800

\subsection{Mini PLC Zelio}

Zelio "Smart Relay" dibuat oleh Schneider Telemecanique yang didesain untuk automated system aplikasi industri dan komersial. Tujuan dibuatkan zelio adalah untuk menggantikan logika dan pengerjaan sirkit kontrol relay yang merupakan instalasi langsung. Dengan Smart Relay, rangkaian kontrol cukup dibuat dengan software.

Zelio tersedia dalam 2 model yaitu Modul Compact dan Model Modular. Perbedaannya adalah pada model modular dapat ditambahkan extension module sehingga dapat ditambahkan input dan output sampai dengan 40 I/O. Selain itu model modular juga dapat dimonitor dengan jarak jauh dengan penambahan modul melalui komunikasi jaringan Modbus. Software yang digunakan untuk zelio ini adalah Zelio Soft 2 yang menggunakan bahasa ladder diagram dan function block diagram (FBD) [13][14].

\subsection{Driver Motor}

Driver motor DC digunakan untuk mengendalikan putaran motor apakah motor diinginkan berputar searah jarum jam atau berputar berlawanan dengan jarum jam. Oleh karena itu digunakan konfigurasi teori jembatan $\mathrm{H}$ (H-Bridge), yang akan mengendalikan motor kedua arah secara bergantian.

Secara konsep rangkaian ini terdiri dari 4 transistor sebagai saklar yang dikonfigurasikan berpasangan. Transistor Q1 yang dikonfigurasikan dengan transistor Q3. Sedangkan transistor Q2 dikonfigurasikan dengan transistor Q4. Pada saat transistor Q1 dan Q3 aktif maka motor akan berputar ke kanan. Dan pada saat transistor Q2 dan Q4 aktif maka motor akan berputar ke kiri [8]. Dapat dilihat gambar rangkaian $\mathrm{H}$-Bridge driver motor dc pada Gambar 2.3.

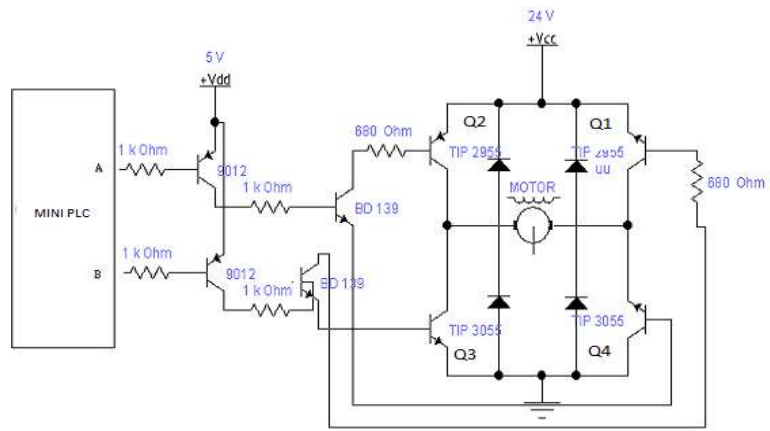

Gambar 2.3 H-Bridge Driver Motor DC 


\subsection{Motor DC}

Motor DC atau motor arus searah adalah suatu mesin yang berfungsi untuk mengubah tenaga listrik arus searah menjadi tenaga gerak atau tenaga mekanik. Motor DC mempunyai dua terminal elektrik. Dengan memberikan beda tegangan pada kedua terminal tersebut, motor akan berputar pada satu arah, dan bila polaritas tegangan tersebut dibalik maka arah putaran motor akan terbalik pula. Polaritas dari tegangan yang diberikan pada dua terminal menentukan arah putaran motor sedangkan besar dari beda tegangan pada kedua terminal menentukan kecepatan motor.

Keunggulan dari motor dc adalah lebih cocok digunakan pada aplikasi yang menggunakan kecepatan tinggi dan torsi yang cukup besar karena motor dc baik kecepatan, laju dan arah putarnya dapat diatur dengan mudah sesuai dengan keinginan. Beberapa metode yang digunakan adalah $\mathrm{H}$-Bridge, PWM, discrete PID, flyback, voltage comparator, dan lain-lain [14][15].

\section{METODE}

Berikut blok diagram dari konfigurasi sistem perangkat keras sebelum melangkah ke prinsip dan cara kerja dari perangkat secara keseluruhan pada Gambar 3.1.

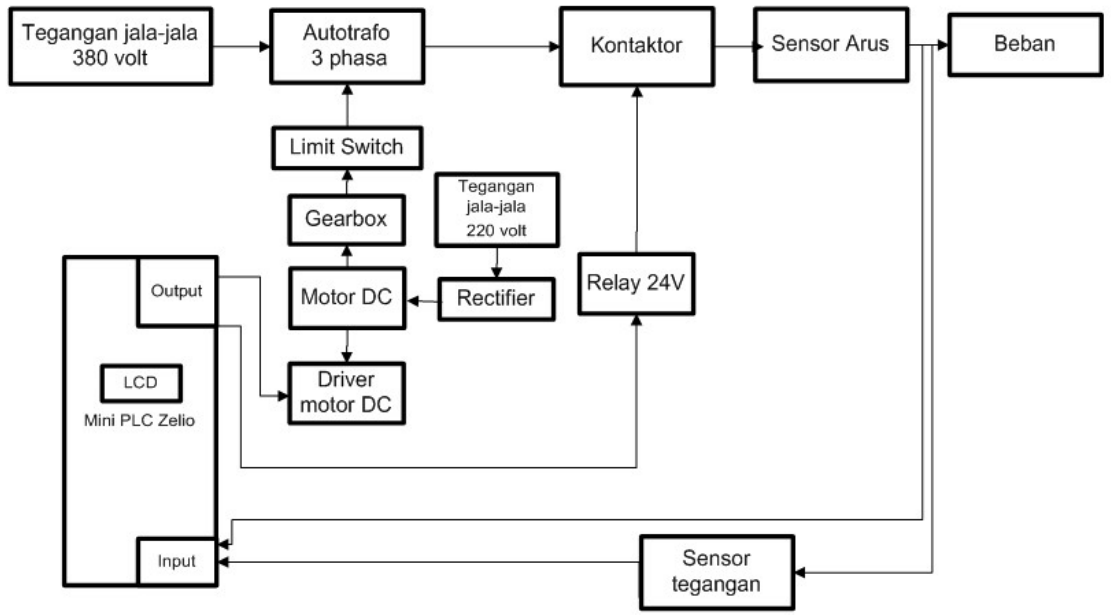

Gambar 3.1 Block Diagram Sistem

Sistem kerja dari block diagram diatas adalah ketika sumber tegangan 380 volt dihubungkan pada autotrafo 3 phasa, sensor tegangan (potensial transformer) mendeteksi over voltage atau under voltage, maka sensor tegangan tersebut akan mengeluarkan output berupa tegangan [16]. Tegangan tersebut masuk ke rangkaian pengolah signal conditioning ADC (Analog Digital Converter) kemudian diteruskan ke mini PLC zelio untuk diproses [18]. Setelah mendapat masukan dari sensor tersebut maka zelio akan memberi perintah apabila sensor tegangan mendeteksi tegangan lebih dari set point maka zelio akan mengaktifkan driver motor dc untuk menggerakan motor berputar ke kiri. Dan sebaliknya apabila sensor tegangan mendeteksi tegangan kurang dari set point maka zelio akan mengaktifkan driver motor dc untuk menggerakan motor berputar ke kanan [19]. Alat ini dilengkapi sensor arus WCS1800 yang berfungsi mendeteksi arus lebih, keluaran dari sensor arus tersebut akan diolah oleh zelio untuk mengaktifkan kontaktor untuk memutus sumber dengan beban [17][20]. Alat ini juga dilengkapi limit switch sebagai pengaman tuas autotrafo dan pengaman motor dc supaya tidak terus bekerja ketika 
mencapai titik maksimum atau minimum dari range tuas autotrafo [8]. Potensio difungsikan sebagai pengganti keypad yang digunakan sebagai input nilai set point tegangan yang di inginkan.

\subsection{Sensor Tegangan (Potensial Transformer)}

Perencanaan sensor tegangan ini memakai trafo step down yang memiliki kriteria tegangan primer sebesar 420 Volt dan tegangan sekundernya sebesar 12 Volt. Setelah itu tegangan AC nya disearahkan dengan 4 buah diode serta difilter ripplenya menggunakan sebuah kapasitor bernilai kecil. Setelah didapatkan tegangan DC maka akan diberi rangkaian voltage devider untuk mendapatkan tegangan maksimal DC 10V. Hal ini di karenakan ADC zelio hanya mampu menerima inputan 0 - 10V [11][16]. Untuk mendapatkan tegangan $10 \mathrm{~V}$ tersebut dapat diperoleh dengan perhitungan :

Keterangan:

$$
V n=\frac{R 2}{R 1+R 2} \times V m
$$

$\mathrm{Vn} \quad=10 \mathrm{~V}$

$\mathrm{Vm} \quad=12 \mathrm{~V}$

$\mathrm{R} 1=10 \mathrm{~K} \Omega$ (referensi di pasaran)

$\mathrm{R} 2=2 \mathrm{~K} \Omega$ (didapat dari hasil perhitungan)

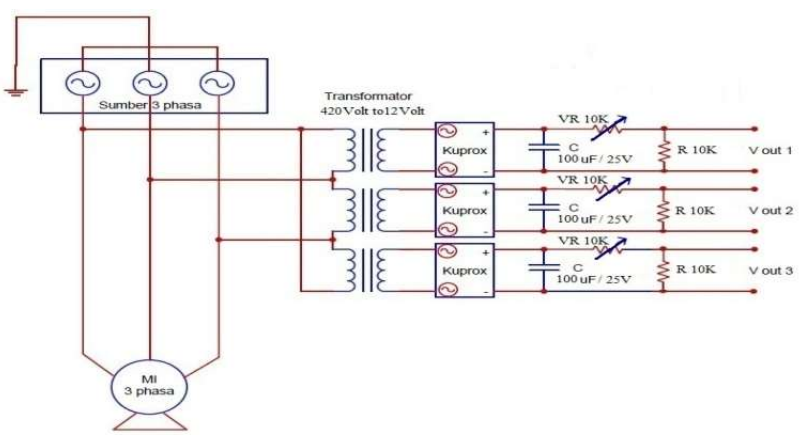

Gambar 3.2 Rangkaian Sensor Tegangan

\subsection{Sensor Arus (WCS1800)}

Sensor WCS1800 menggunakan modul jadi pabrikan dari Winson. Hasil keluaran WCS1800 masih berupa sinyal tegangan AC dan memiliki komponen DC sebesar 2,5 volt ketika nol. Agar ouput sensor dapat diolah ke ADC zelio, maka langkah awal adalah merubah tegangan AC menjadi DC menggunakan rangkaian penyearah.

Setelah dilakukan percobaan, ternyata hasil keluarannya sudah menjadi tegangan DC namun masih mengandung komponen DC 2.5 Volt turun menjadi 1,6 Volt. Agar komponen DC 1.6 Volt hilang menjadi 0 Volt, maka rangkaian dimodifikasi menggunakan rangkaian pembagi tegangan (voltage divider) dan selanjutnya dikuatkan menggunakan rangkaian penguat Op-Amp 741 non Inverting dengan gain 6 kali sebagai penguat tegangan pada keluaran sensor arus WCS1800 yang sangat kecil sebesar $60 \mathrm{mV} / \mathrm{A}$ [20]. Berikut adalah rangkaian modifikasi WCS1800 pada Gambar 3.3. 


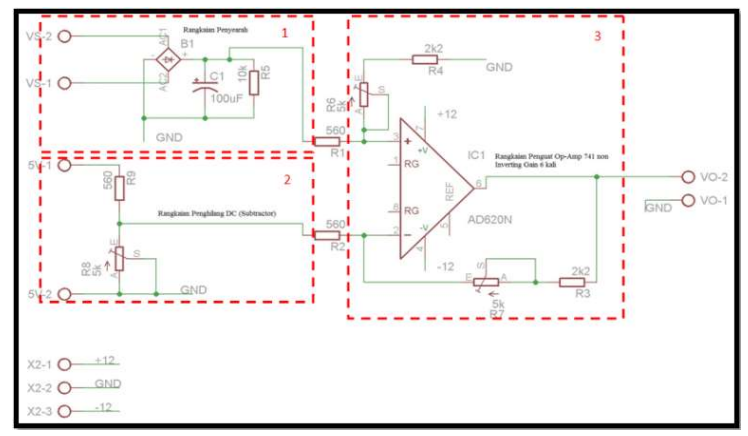

Gambar 3.3 Rangkaian Sensor Arus WCS1800

\subsection{Mini PLC Zelio dan Software "Zelio Soft"}

Mini PLC Zelio"Smart Relay" yang digunakan adalah tipe SR3B261BD yang memiliki jumlah input discrete 16 buah, input analog 6 buah dan jumlah output 10 relay [18].

PLC zelio menggunakan software Zelio Soft2 dan untuk pemrograman Zelio soft dapat menggunakan Ladder Language atau FBD (Function Block Diagram) Language [21].

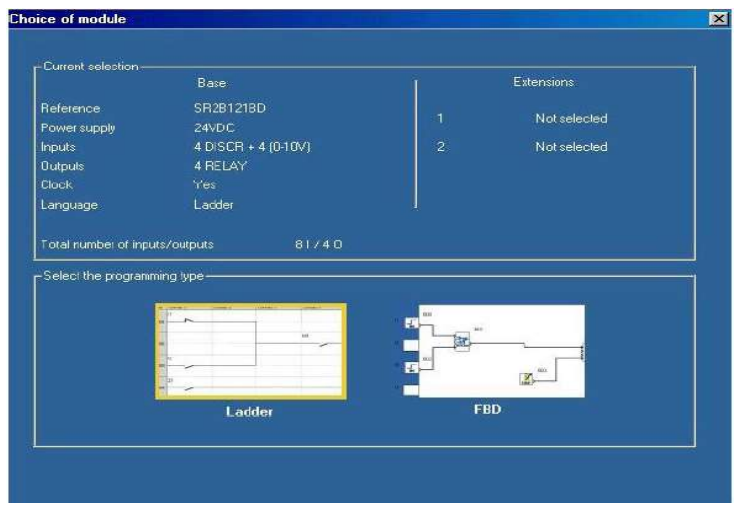

Gambar 3.4 Ladder Diagram dan FBD

\subsection{Driver Motor DC}

Rangkaian driver motor DC menggunakan Embedded Module Series (EMS) 2 A Dual $\mathrm{H}$-Bridge merupakan produk dari Innovative Electronic yang berupa driver $\mathrm{H}$ Bridge yang didesain untuk menghasilkan drive 2 arah dengan arus kontinyu sampai dengan 2 A pada tegangan 4,8 Volt sampai 46 Volt [22].

\subsection{Motor DC}

Motor DC memiliki kemampuan torsi sesuai dengan kebutuhan. Untuk menentukan nilai torsi motor dc dilakukan percobaan pengukuran kekuatan tuas autotrafo menggunakan timbangan digital dan stopwatch. Ditemukan: $M=6.14 \mathrm{~kg}$, $1=3 \mathrm{~cm}$ dan $\mathrm{t}=15.5$ detik $(\mathrm{s})$ dalam 1 putaran, maka:

$\mathrm{T}=\mathrm{m} \times 1 \longrightarrow \quad 6.14 \times 3=18.3$ kgf.cm

Sehingga motor dc yang digunakan adalah motor dc yang memiliki $\mathrm{T}=18.3$ kgf.cm dan semakin besar dari nilai tersebut semakin baik. Akhirnya di dapat motor dc bekas yang diambil dari mesin fotokopi yang tidak terpakai dan sudah ada gearboxnya. 
Karena dibutuhkan putaran kecil, untuk menentukan perhitungan gigi reduksi gearbox yang benar antara motor dc dengan tuas autotrafo adalah Diketahui range tegangan pada output autotrafo $=0-430$ volt dalam 1 putaran $\left(352^{\circ}\right)$.

Sesuai rumus:

$$
1 \mathrm{rad}=\frac{360}{2 \pi}=57.32^{\circ} \longrightarrow 352^{\circ}=\frac{352}{57.32}=6.14 \mathrm{rad}
$$

Kecepatan sudut (angular velocity)

$\omega=\frac{6.14}{15.5} \mathrm{rad} / \mathrm{s}=0.4 \mathrm{rad} / \mathrm{s} \quad(\mathrm{t}=15.5)$

Nilai gear box di dapat kecepatan $=9.55 \times 0.4 \mathrm{rad} / \mathrm{s}=3.82 \mathrm{rpm}$

Berdasarkan kondisi di lapangan untuk mendapatkan gearbox sesuai perhitungan itu sulit, akhirnya di dapatkan ide menggunakan gear sepeda pancal depan (36) dan belakang (12) beserta rantai yang digunakan dengan gear ratio $1: 3$ dari spesifikasi kecepatan motor dc 22 rpm menjadi $6 \mathrm{rpm}$.

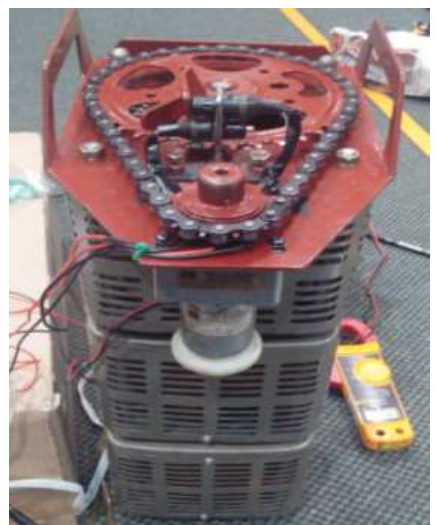

Gambar 3.5 Gigi reduksi Antara Motor DC dengan Tuas Autotrafo

\section{HASIL DAN PEMBAHASAN}

\subsection{Pengujian integrasi sistem secara keseluruhan}

Pada tahap ini dilakukan pengujian sistem secara keseluruhan. Sebelumnya akan dijelaskan sedikit program FBD pada Gambar 4.7 adalah sistem kerja motor berdasarkan set poin tegangan dengan toleransi $\pm 1.3 \%$ dari 380 volt, sehingga respon motor akan bekerja cepat berdasarkan range tegangan antara 375 volt dan 385 volt. Hal ini dimaksudkan agar mengetahui gerakkan dari respon motor dan mengharapkan tegangan selalu di 380 volt seperti kerja pada stavolt 220 volt. Namun hal ini tidak merubah acuan set point tegangan yang di ijinkan dengan tegangan 380 volt toleransi $+5 \%$ untuk over voltage dan $-10 \%$ untuk under voltage sesuai SPLN No. 1:1995 Pasal 4. Untuk set point tegangan $+5 \%$ dan $-10 \%$ dari 380 volt tetap digunakan sebagai parameter gangguan pada LCD zelio, lampu indikator serta sebagai acuan dari kinerja motor agar dapat terus merespon tegangan masukkan berapapun asalkan dalam batas kemampuan spesifikasi dari autotrafo tersebut. 


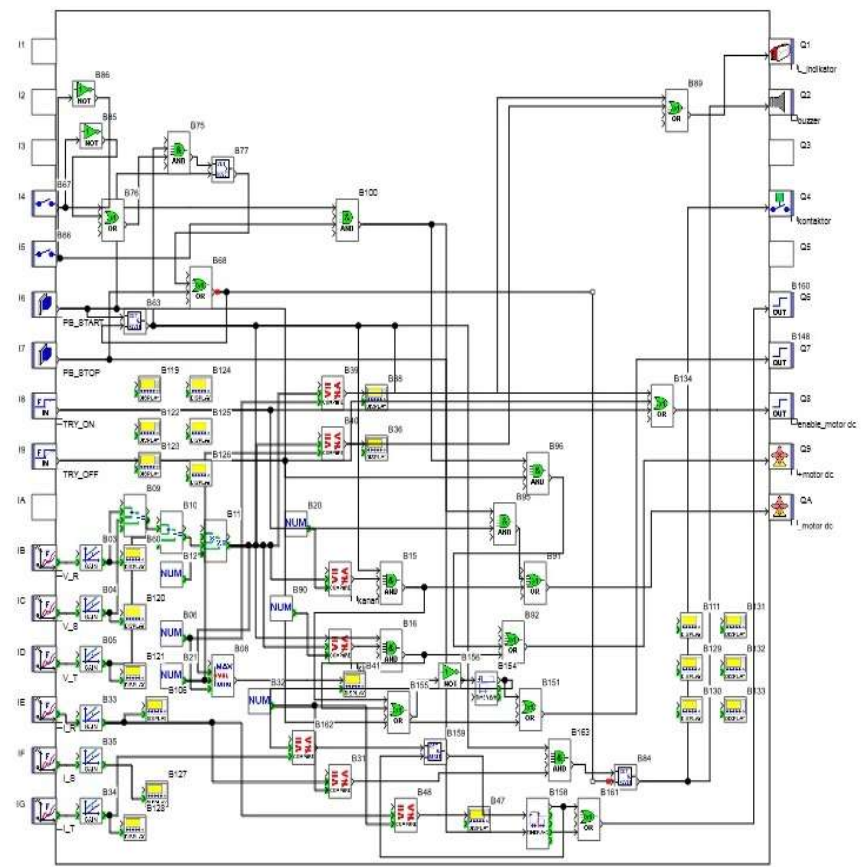

Gambar 4.7 Function Block Diagram Zelio

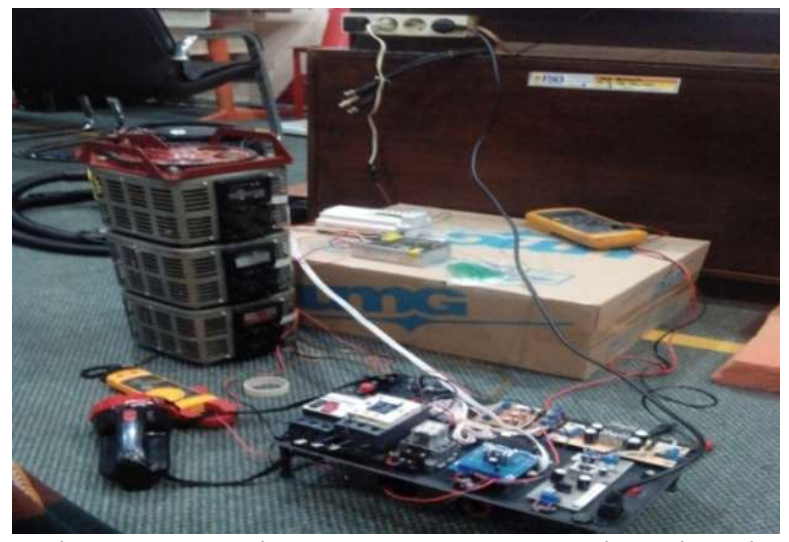

Gambar 4.8 Hardware sistem secara keseluruhan

Pada pengujian sistem secara keseluruhan dilakukan melalui 2 tahap yaitu pada saat kondisi tidak berbeban dan berbeban ketika sistem tetap bekerja (online) untuk mengetahui perbandingan kemampuan dan respon alat ini bekerja. Yang pertama sistem dilakukan tanpa ada beban dengan menggunakan input autotrafo tambahan sebagai pengganti gangguan over voltage dan under voltage pada Tabel 4.5 dan yang kedua sistem dilakukan dengan ada beban pada Tabel 4.6.

Tabel 4.5 Pengujian Sistem Tidak Berbeban

\begin{tabular}{|c|c|c|c|c|c|c|c|}
\hline $\begin{array}{c}\text { Autotrafo } \\
\text { Under } \\
\text { Voltage }\end{array}$ & $\begin{array}{c}\text { Respon } \\
\text { Time } \\
(\mathbf{s})\end{array}$ & $\begin{array}{c}\text { Tegangan } \\
\text { Output } \\
\text { Autotrafo }\end{array}$ & $\begin{array}{c}\text { Error } \\
\mathbf{( \% )}\end{array}$ & $\begin{array}{c}\text { Autotraf } \\
\text { o Over } \\
\text { Voltage }\end{array}$ & $\begin{array}{c}\text { Respon } \\
\text { Time } \\
(\mathbf{s})\end{array}$ & $\begin{array}{c}\text { Tegangan } \\
\text { Output } \\
\text { Autotravo }\end{array}$ & $\begin{array}{c}\text { Erro } \\
\text { r (\%) }\end{array}$ \\
\hline 330 Volt & 0.65 & 382 Volt & 0.52 & 420 Volt & 0.77 & 379 Volt & 0.26 \\
\hline 340 Volt & 0.48 & 381 Volt & 0.20 & 410 Volt & 0.64 & 379 Volt & 0.27 \\
\hline 350 Volt & 0.31 & 380.3 Volt & 0.07 & 400 Volt & 0.50 & 380.2 Volt & 0.05 \\
\hline 360 Volt & 0.18 & 380.3 Volt & 0.02 & 390 Volt & 0.21 & 380.1 Volt & 0.02 \\
\hline
\end{tabular}


Tabel 4.6 Pengujian Sistem Berbeban

\begin{tabular}{|c|c|c|c|c|c|c|c|}
\hline $\begin{array}{c}\text { Autotrafo } \\
\text { Under } \\
\text { Voltage }\end{array}$ & $\begin{array}{c}\text { Respon } \\
\text { Time } \\
\text { (s) }\end{array}$ & $\begin{array}{c}\text { Tegangan } \\
\text { Output } \\
\text { Autotrafo }\end{array}$ & $\begin{array}{c}\text { Error } \\
\text { (\%) }\end{array}$ & $\begin{array}{c}\text { Autotraf } \\
\text { o Over } \\
\text { Voltage }\end{array}$ & $\begin{array}{c}\text { Respon } \\
\text { Time } \\
\text { (s) }\end{array}$ & $\begin{array}{c}\text { Tegangan } \\
\text { Output } \\
\text { Autotravo }\end{array}$ & $\begin{array}{c}\text { Error } \\
\text { (\%) }\end{array}$ \\
\hline 330 Volt & 0.68 & 381 Volt & 0.20 & 420 Volt & 0.79 & 379 Volt & 0.26 \\
\hline 340 Volt & 0.50 & 381 Volt & 0.20 & 410 Volt & 0.66 & 379 Volt & 0.26 \\
\hline 350 Volt & 0.33 & 380.1 Volt & 0.02 & 400 Volt & 0.51 & 380.1 Volt & 0.02 \\
\hline 360 Volt & 0.25 & 379.9 Volt & 0.02 & 390 Volt & 0.27 & 380.1 Volt & 0.02 \\
\hline
\end{tabular}

Pada Tabel 4.5 dan Tabel 4.6 dapat dilihat perbedaan dan perbandingan dari sistem ketika tidak berbeban dan sistem dibebani tidak terlalu mengalami perubahan signifikan dikarenakan beban yang digunakan adalah beban motor AC 3 phasa yang memiliki kapasitas arus sangat kecil yaitu sekitar \pm 0.35 Ampere dengan daya sebesar $1.49 \mathrm{KW}$, sehingga terjadi sedikit perubahan tegangan dengan ratarata \pm 1 volt. Namun waktu respon motor kembali ke set point 380 volt $( \pm 1.3 \%)$ pada program FBD yang dibuat, tegangan input yang kurang atau lebih dari 380 volt sampai kembali ke set point variable tegangan 380 volt ketika tidak berbeban yaitu pada saat under voltage adalah \pm 0.40 sekon dengan persen error adalah $\pm 0.20 \%$ dan pada saat over voltage adalah \pm 0.53 sekon dengan persen error adalah \pm 0.15 $\%$. Serta ketika berbeban yaitu pada saat under voltage adalah \pm 0.44 sekon dengan persen error adalah $\pm 0.20 \%$ dan pada saat over voltage adalah \pm 0.55 sekon dengan persen error adalah $\pm 0.20 \%$.

Pengujian terakhir adalah membandingkan respon motor dari autotrafo yang telah dibuat dengan kinerja stavolt servo motor 220 volt, apakah sudah cukup cepat dalam mengembalikan ke set point tegangan ketika terjadi gangguan. Dengan menggunakan input autotrafo 1 phasa tambahan sebagai pengganti gangguan over voltage dan under voltage. Selanjutnya sistem dilakukan menggunakan beban setrika dengan spesifikasi 220 volt, 300 watt dan 1.4 Ampere. Dapat dilihat pada Gambar 4.9 dan Tabel 4.7.

Tabel 4.7 Pengujian Stavolt Berbeban dan Tidak Berbeban

\begin{tabular}{|c|c|c|c|c|}
\hline \multirow{2}{*}{ Kondisi } & $\begin{array}{c}\text { Teganggan } \\
\text { Setting } \\
\text { Autotrafo 1 } \boldsymbol{\varphi}\end{array}$ & Status & $\begin{array}{c}\text { Respon } \\
\text { Time (s) }\end{array}$ & $\begin{array}{c}\text { Tegangan } \\
\text { Output } \\
\text { Stavolt }\end{array}$ \\
\hline \multirow{2}{*}{ No Load } & 210 Volt & Under Voltage & 0.19 & 221.5 Volt \\
\cline { 2 - 5 } & 230 Volt & Over Voltage & 0.25 & 240 Volt \\
\hline \multirow{2}{*}{ Load } & 210 Volt & Under Voltage & 0.32 & 222.4 Volt \\
\cline { 2 - 5 } & 230 Volt & Over Voltage & 0.28 & 243.4 Volt \\
\hline
\end{tabular}

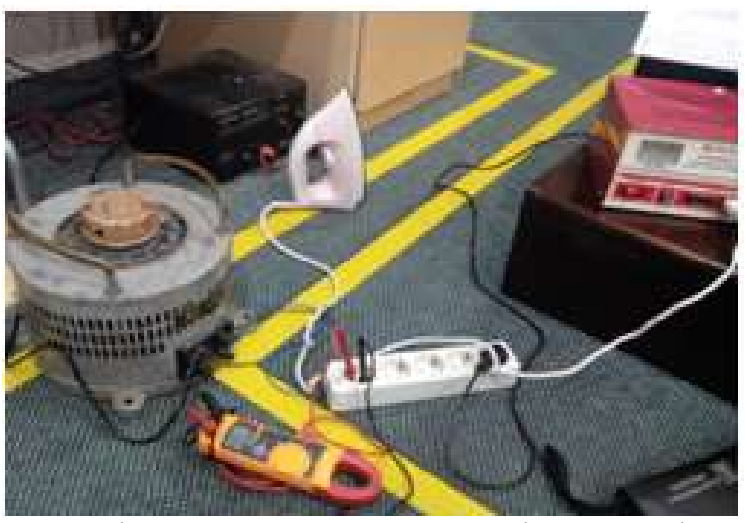

Gambar 4.9 Pengujian Stavolt 220 Volt 
Pada Tabel 4.7 dapat dilihat bahwa respon kerja motor servo stavolt 220 volt lebih cepat dari autotrafo yang dibuat. Pengujian dilakukan menggunakan stopwatch manual untuk mengukur waktu kembali penunjukkan pada jarum stavolt ketika autorafo 1 phasa diturunkan tegangan sebesar 210 volt sebagai gangguan undervoltage, maka waktu respon stavolt adalah 0.19 sekon. Lalu ketika autotrafo 1 phasa dinaikkan tegangan yaitu 230 volt sebagai gangguan over voltage, maka waktu respon stavolt adalah 0.25 sekon. Dan pengujian selanjutnya menggunakan beban setrika, waktu respon stavolt ketika under voltage adalah 0.32 sekon dan ketika over voltage adalah 0.28 sekon.

Data tersebut menunjukkan bahwa waktu respon autotrafo yang dibuat memang lebih lambat \pm 0.1 sekon dari waktu respon stavolt ketika kembali ke set point. Namun, autotrafo ini memiliki banyak kelebihan dibandingkan stavolt antara lain:

1. Gangguan dapat lebih mudah dipantau oleh user, karena autotrafo ini dapat digunakan sebagai monitoring tegangan dan arus melalui parameter pada tampilan LCD, lampu indikator, dan buzzer.

2. Dapat memperbaiki tegangan dengan mempertahankan tegangan outputnya menjadi stabil saat terjadi gangguan under voltage atau over voltage.

3. Autotrafo yang dibuat dilengkapi pengaman / proteksi terhadap gangguan over current sehingga peralatan lebih aman dan safety.

4. Autotrafo juga dapat digunakan untuk uji lab karena set point variabel tegangan pada zelio bisa diatur sesuai dengan yang dikehendaki.

Dengan demikian peralatan terhindar dari resiko kerusakan yang disebabkan oleh gangguan under voltage, over voltage, dan over current. Serta memperpanjang lifetime dari peralatan tersebut.

\section{KESIMPULAN}

Setelah dilakukan proses perencanaan, pembuatan dan pengujian alat serta dengan membandingkan dengan teori-teori penunjang, dan dari data yang didapat, maka dapat disimpulkan :

1. Sensor arus WCS1800 mampu mensensing arus AC dengan hasil yang linear. Pembacaan sensor arus WCS1800 adalah $30 \mathrm{mV}$ untuk tiap 0.5A arus AC yang disensor.

2. Sensor tegangan dengan Potensial Transformer (PT) mempunyai hasil sensing yang linear dan dapat digunakan untuk mensensing tegangan hingga 420 volt . Pembacaan sensor tegangan PT adalah 0,46 volt untuk tiap 20 volt tegangan AC yang disensor.

3. Waktu respon motor alat ini kembali ke set point ketika tidak berbeban yaitu pada saat under voltage adalah \pm 0.40 sekon dengan persen error adalah $\pm 0.20 \%$ dan pada saat over voltage adalah \pm 0.53 sekon dengan persen error adalah \pm 0.15 $\%$. Serta ketika berbeban yaitu pada saat under voltage adalah \pm 0.44 sekon dengan persen error adalah $\pm 0.20 \%$ dan pada saat over voltage adalah \pm 0.55 sekon dengan persen error adalah $\pm 0.20 \%$.

4. Dengan adanya Autotrafo ini, maka peralatan terhindar dari resiko kerusakan yang disebabkan oleh gangguan under voltage, over voltage, dan over current. Serta memperpanjang lifetime dari peralatan tersebut. 


\section{DAFTAR RUJUKAN}

[1] Al Haqim, M.Abdul Aziz, Pengaturan Tegangan Pada Autotrafo 3 Phasa Berbasis Mikrokontroler (Software), jurusan teknik elektro industri PENS-ITS, 2011.

[2] Triarsunu, Nurandy, Pengaturan Tegangan Pada Autotrafo 3 Phasa Berbasis Mikrokontroler (Hardware), jurusan teknik elektro industri PENS-ITS, 2011.

[3] Prasetyo, Didik, Perancangan Proteksi Under Voltage Dan Over Voltage Pada Motor Induksi 3 Fasa Berbasis Mikrokontroler ATMEGA32, jurusan teknik elektro PENS-ITS, 2009.

[4] Makalah Word Document berjudul Modul Praktikum Pengenalan Pengaturan Stabilisator Tegangan AC, laboratorium Perangkat Keras STMIK Akakom Yogyakarta.

[5] Muztaqim, Pengetesan Rugi-Rugi Transformator 3 Phase berbasis IBM PC, jurusan teknik elektro industri PENS-ITS, 2007.

[6] Darmadi, Budiyanto dan Prayitno, Agung, Aplikasi PLC Schneider Pada Mesin Pengepakan Telur, jurusan teknik elektro Universitas Surabaya, 2013.

[7] LP, Bambang, Pembuatan Roda Gigi Reduksi Pemutar Variak Sistem Tegangan Tinggi MBE Industri Latek, Jurnal Pusat Teknologi Akselerator dan Proses Bahan-BATAN, Babarsari Yogyakarta, 27 Juli 2011.

[8] Zamroni, Muhammad, Kendali Motor DC Sebagai Penggerak Mekanik Pada Bracket LCD Proyektor Dan Layar Dinding Berbasis Mikrokontroller AT89S51, jurusan D3 teknik elektro Fakultas Teknik Universitas Diponegoro Semarang.

[9] M. Nur Putra, Andi, Studi Analisa Kestabilan Tegangan Sistem 150 KV Berdasarkan Perubahan Tegangan (Aplikasi PT. PLN Batam), jurusan teknik elektro Fakultas Teknologi Industri Institut Teknologi Padang.

[10] Nur Widiastuti, Avrin, Studi Kestabilan Tegangan Jaringan IEEE 9 Bus Menggunakan Indeks Kestabilan Tegangan, jurusan teknik elektro Fakultas Teknik UGM Yogyakarta, Indonesia, 14 - 15 November 2013.

[11] Prasetyo, Harry, Rancang Bangun Monitoring Tegangan, Arus, Dan Power Faktor Menggunakan Gelombang Radio Serta Perbaikan Power Faktor Untuk Beban Dinamik Pada Rumah Tangga, jurusan teknik elektro industri PENS ITS, 2008.

[12] Susi Putra, Alex, Rancang Bangun Sistem Proteksi Motor Induksi Tiga Phasa Terhadap Gangguan Arus Lebih Dan Suhu, jurusan teknik elektro Fakultas Teknik Universitas Pakuan, 2013.

[13] Makalah PDF berjudul Modul Praktikum PLC (Zelio) Fix 1, laboratorium teknik Elektro Universitas Islam Kadiri - Kediri.

[14] Wiria Nugraha, Deny, Sistem Pengaturan Mesin Pemotong Kentang Berbasis Programmable Logic Controller, jurusan teknik elektro Fakultas Teknik 
Universitas Tadulako Palu, jurnal SMARTek, Vol. 8 No. 4, Nopember 2010: $270-279$.

[15] Budi Hartono, Nanang, Pengaturan Posisi Motor Servo DC Dengan Metode P, PI, Dan PID, jurusan teknik elektronika PENS - ITS.

[16] Pradigta, Lucky, Motor induksi 3 phase terhadap gangguan unbalance voltage dan overload, jurusan teknik elektro industri PENS - ITS, 2008.

[17] Ridwan, Ahmad, Rancang Bangun Sistem Proteksi Motor Induksi Tiga Phasa Terhadap Gangguan Arus Berbasis Mikrokontroller, jurusan teknik elektro industri PENS-ITS, 2014.

[18] Datasheet of Zelio SR3B261BD. Digiware.

[19] Nur Harijadi, Indra, Pembuatan Sistem Pengemudian Otomatis Pada Kendaraan Beroda Dengan Model Pembelajaran Offline, jurusan teknik elektronika PENS-ITS.

[20] Datasheet of Current Sensor WCS1800. Winson.

[21] Nurcahyo, Adi, Sinkronisasi Dan Pengamanan Modul Generator Lab-TST Berbasis PLC (Software), jurusan teknik elektro PENS-ITS, 2008.

[22] Datasheet of EMS 2A DUAL H-BRIDGE. Digiware. 